\title{
Explaining the role of organizational culture on succession-planning at the Ministry of Health and Medical Education: A qualitative study
}

\author{
Mohammad Mehrtak ${ }^{1}$, Esmaeil Farzaneh², Shahram Habibzadeh³, Aziz Kamran ${ }^{4}$, Hamed Zandian ${ }^{5}$, Abdollah \\ Mahdavi $^{1}$
}

${ }^{1}$ Ph.D. Assistant Professor, Department of Health Information Management, Faculty of Paramedical Sciences, Ardabil University of Medical Sciences, Ardabil, Iran

${ }^{2}$ M.D. Associate Professor, Department of Forensic Medicine and Toxicology, Faculty of Medicine, Ardabil University of Medical Sciences, Ardabil, Iran

${ }^{3}$ M.D. Associate Professor, Department of Infectious Diseases, Faculty of Medicine, Ardabil University of Medical Sciences, Ardabil, Iran

${ }^{4} \mathrm{Ph}$.D. Assistant Professor, Department of Public Health, Khalkhal Faculty of Medical Sciences, Ardabil University of Medical Sciences, Ardabil, Iran

${ }^{5}$ Ph.D. Assistant Professor, Department of Community Medicine, Faculty of Medicine, Ardabil University of Medical Sciences, Ardabil, Iran

\section{Type of article: Original}

\begin{abstract}
Background: Developing and guiding new knowledge are futile unless the organizational culture can also be transformed. Future leaders cannot emerge out of an organizational environment that is not conducive to the accumulation of experiences.

Objective: The aim of this study was to explore the role of organizational culture in creating a successionplanning system at the Ministry of Health and Medical Education in 2014.

Methods: The present qualitative framework analysis held interviews with 23 director generals, administrative directors and deputies from the headquarters of the Iranian Ministry of Health and Medical Education in 2014 who were selected through snowball sampling. The data obtained were analyzed in MAXQDA-10. Codes were extracted using inductive techniques.

Results: The cultural factors affecting succession-planning at the Ministry of Health and Medical Education were identified and classified under three main areas, including the cultural factors related to the directors with four themes (Directors' job security, Constructive competition, Transparency and trust development, Creating opportunities), to the personnel with four themes (Organizational identity and loyalty, Trust in the organization, Talent and merit, Peer envy) and to the system with two themes (Values and beliefs, Politicization).

Conclusion: Findings of the study show that establishment and institutionalization of the succession planning to the Ministry of Health and Medical Education is deeply affected by the components of organizational culture. Accordingly, unprofessional organization culture can deprive the organization of numerous advantages in multiple-succession planning.
\end{abstract}

Keywords: Organizational culture, Planning, Talent, Qualitative research

\section{Introduction}

Today and every day, the lives of vast numbers of people lie in the hands of health systems. The ultimate responsibility for the overall performance of a country's health system lies with its government, which in turn

\section{Corresponding author:}

Associate Professor Dr. Shahram Habibzadeh, Department of Infectious Diseases, Faculty of Medicine, Ardabil University of Medical Sciences, Ardabil, Iran.

Tel: +98.9144519670, Fax:+98.4533522082, Email: shahramhabibzadeh@gmail.com

Received: January 21, 2017, Accepted: July 03, 2017, Published: November 2017

iThenticate screening: July 04, 2017, English editing: November 07, 2017, Quality control: November 12, 2017

This article has been reviewed / commented by three experts

(C) 2017 The Authors. This is an open access article under the terms of the Creative Commons Attribution-NonCommercialNoDerivs License, which permits use and distribution in any medium, provided the original work is properly cited, the use is non-commercial and no modifications or adaptations are made. 
should involve all sectors of society in its stewardship. The careful and responsible management of the well-being of the population is the very essence of good government (1). One of the more prominent issues in management science in recent years is organizational culture. Culture is a complex totality of distinctive spiritual, material, intellectual and mental aspects that describe a society or social group (2). Organizational culture is a collection of assumptions, values and beliefs adopted and interpreted by the members of an organization that represent the actual values declared by the organization and its members )3(. In other words, it is a pattern of norms, values, beliefs and attitudes that affect the behaviors of the members of the organization (4). Unless the ruling organizational culture is transformed, the development and guidance of new knowledge will be futile (5). Organizational culture creates a sense of identity and commitment in members that surpasses their personal gain and brings persistence and stability to the system, and shapes and forms the personnel's behaviors as a factor of control (6). Organizational culture is a multidimensional construct that should not be analyzed by merely considering a few features and neglecting the dynamic relationships between the features (7). Organizational culture affects all the aspects of an organization and strengthens it through mutual beliefs and values; furthermore, it affects people's attitudes and personal behaviors, motivation, job satisfaction, employee commitment, structural design and organizational systems, target-setting, the development and implementation of policies and strategies, etc. It is only through evaluating, transforming and developing an appropriate organizational culture that the patterns of interaction within the organization can also change, albeit gradually (8). Cultural, gender and age diversity in the workforce, especially in leadership positions, ensures the strength and flexibility required for inevitable environmental changes and challenges in public health organizations. The power that age and cultural diversity bring into an organization is a valuable asset (9). Succession-planning is a complex and challenging process affected by organizational culture (10). Future leaders cannot emerge out of an organizational environment that is not conducive to the accumulation of experiences. Succession-planning should emphasize the acquisition of knowledge and skills and the promotion of capabilities, and should also take into account the cultural capacity of the organization for the growth of its trainees (11). Succession-planning focuses on the development of a systematic program for finding potential talents and providing development paths for these talents (12). If senior managers fail to perceive the need for these measures, successionplanning cannot be effective (13).

Succession-planning management brings competent individuals into the organization; however, it necessitates further organizational resources and requires a culture that understands the value of pools of talents and that is able to proceed with the process of succession-planning along with the other routine activities of the organization (14). In today's complex and challenging world of healthcare, leadership is crucial to the success of healthcare organizations, and the leadership's succession-planning is a key strategy for ensuring the continuation of leadership and the development of talents within the organization (15). Demographic changes in the workforce and the shortage of healthcare professionals are potentially serious challenges to the success and continuity of healthcare organizations (16). Healthcare organizations are therefore obliged to search incessantly for the next generation of managers (17). Organizational culture is currently such a prominent issue that management scholars consider the transformation of the existing cultural values and the establishment of new ones as the main duty of leaders (18). It seems in the current situation, the existing organizational culture in the Ministry of Health and Medical Education does not have the capacity to accept and institutionalize the succession planning. So the present study was conducted to explore the views of key directors of the Ministry of Health and Medical Education on the effect of organizational culture on succession-planning.

\section{Material and Methods}

\subsection{Research design and setting}

The present study was conducted at the Iranian Ministry of Health and Medical Education in 2014 using the qualitative framework analysis. To achieve maximum sample variation and better conceptualization, non-random snowball sampling was used to select consenting participants from the main directors of the seven deputies of the Ministry of Health and Medical Education as key informants. Data saturation was reached after the 23rd interview with the key informants.

\subsection{Interview and data collection}

The tool used in this step of the study was an interview guide form. For the semi-structured interviews, a suitable time and place was arranged by visiting the headquarters and offices and after presenting the interview guide protocol. Each of the interviews lasted between 25 and 90 minutes and informed consent was taken from participants to record the interviews, which were immediately transcribed and typed by the researcher. The framework method was used for analyzing the qualitative data; this method is designed for analyzing qualitative 
data in policy-making studies $(19,20)$. In the first stage of the study, i.e. the introduction, a brief communication content was designed for each interview. In the second stage, i.e. the stage of thematic framework identification, the initial coding framework was formed according to the main areas identified in the review of literature (the deductive reasoning approach) and the new issues that had emerged from the introduction stage (the inductive approach). MAXQDA-10 was used in the third stage, i.e. indexing, and the different parts of the interviews were indexed by one or more codes based on their thematic relationships. These codes were frequently reviewed and modified by the research team members. In the fourth stage, i.e. the tabulation stage, the interviewees' views about each subject were compared using the analytical tables, and the relationship between the main themes and the subthemes was identified and analyzed. In the final stage, i.e. mapping and interpretation, all the subjects were interpreted.

\subsection{Selection criteria}

The study inclusion criteria were: 1) working as Director General or Administrative Director or their deputies, 2) specializing in a relevant field and knowing about succession-planning, 3) interest in the subject and participation in the interviews. The study exclusion criteria were the unwillingness of an individual to participate in the study.

\subsection{Validity and reliability}

Credibility, dependability, confirmability, and transferability were four domains of validity and reliability of the study. In the implementation of the data, to ensure the credibility of the study, double precision was applied. In addition, the interviewed text, extracted themes and sub-themes were shared by four key informant managers, and their corrective comments were used. Triangulation was used to achieve dependability. Data were collected using a combination method including interview recording and simultaneous recording. For confirmability, all activities including the process of performing and the collected information were carefully recorded and the extracted codes of each interview were reviewed and approved by the participants. Finally, to ensure transferability, the research findings were reviewed and approved by six members of the faculty of the university, which is dominated by qualitative studies.

\subsection{Ethics of research}

To comply with ethical considerations, this process was carried out: Letter of permission was obtained from the Research Ethics Committee of Iran University of Medical Sciences (Ref. no.: IUMS/SHMIS-1391/307); the participants were briefed at the beginning of each interview on the study objectives and the confidentiality of their data. The participants also signed written consent forms regarding their participation in the research and to publish findings without mentioning names and descriptions of them. We assured participants of their right to withdraw from the study at any stage.

\section{Results}

All 23 participants of the study were male and were among the Director Generals of the Ministry of Health and Medical Education. None of the participants had assumed their managerial position through formal organizational channels, but were appointed by means of a written notification. Participants' demographic data is shown in Table 1. Table 2 presents the results obtained in three themes and ten subthemes identified and classified as the cultural factors affecting succession-planning at the Ministry of Health and Medical Education. This section explores each one of the factors.

Table1. Participants' demographic data

\begin{tabular}{|l|l|l|l|}
\hline Group & Subgroup & Number & Percent \\
\hline \multirow{3}{*}{ Gender } & Male & 23 & 100 \\
\cline { 2 - 4 } & Female & 0 & 0 \\
\hline \multirow{3}{*}{ Education } & Ph.D. & 7 & 30.4 \\
\cline { 2 - 4 } & Clinical specialist & 16 & 69.6 \\
\hline \multirow{5}{*}{ Work experience (year) } & $<10$ & 2 & 8.7 \\
\cline { 2 - 4 } & $11-19$ & 7 & 30.4 \\
\cline { 2 - 4 } & $20>$ & 14 & 60.9 \\
\hline \multirow{3}{*}{ Management experience (year) } & $<10$ & 4 & 17.4 \\
\cline { 2 - 4 } & $11-19$ & 8 & 34.8 \\
\cline { 2 - 4 } & $20>$ & 11 & 47.8 \\
\hline
\end{tabular}


Table 2. Main areas and themes identified

\begin{tabular}{|c|c|c|}
\hline Theme & Sub theme & Sample Quote \\
\hline \multirow[t]{4}{*}{$\begin{array}{l}\text { Management } \\
\text { Factors }\end{array}$} & $\begin{array}{l}\text { Directors' job } \\
\text { security }\end{array}$ & $\begin{array}{l}\text { Many managers are afraid that implementing succession-planning may } \\
\text { lead to the emergence of a potential successor who has greater capabilities } \\
\text { than the existing manager and that they may thus end up undermining } \\
\text { their own position. }\end{array}$ \\
\hline & $\begin{array}{l}\text { Constructive } \\
\text { competition }\end{array}$ & $\begin{array}{l}\text { When a manager feels that someone is being seen as a potential successor } \\
\text { here, I don't find anything wrong with it, it's not a problem, not a threat. It } \\
\text { only makes the manager work harder to surpass others in all areas of } \\
\text { work. }\end{array}$ \\
\hline & $\begin{array}{l}\text { Transparency and } \\
\text { trust development }\end{array}$ & $\begin{array}{l}\text { We must have clear and fair criteria, which we often do, but still fail to } \\
\text { respect the principles of ethics and equity. So if the system notices that } \\
\text { you set criteria, implement them and respect the principles of equity, they } \\
\text { will gradually form a culture. }\end{array}$ \\
\hline & $\begin{array}{l}\text { Creating } \\
\text { opportunities }\end{array}$ & $\begin{array}{l}\text { When the person in charge sees a worthy individual who is doing things } \\
\text { and giving good ideas, he may feel that the new person can become a } \\
\text { good manager; then he must support him all the way. }\end{array}$ \\
\hline \multirow[t]{4}{*}{$\begin{array}{l}\text { Personnel } \\
\text { Factors }\end{array}$} & $\begin{array}{l}\text { Organizational } \\
\text { identity and loyalty }\end{array}$ & $\begin{array}{l}\text { The employees of this organization do not have great organizational } \\
\text { loyalty, because the managers are mostly brought in from outside. When } \\
\text { the conditions are not conducive to the internal promotion of employees, } \\
\text { organizational loyalty diminishes. }\end{array}$ \\
\hline & $\begin{array}{l}\text { Trust in the } \\
\text { organization }\end{array}$ & $\begin{array}{l}\text { Not choosing competent candidates for managerial positions may convey } \\
\text { the message that the system does not trust its members, and if this } \\
\text { continues, a large number of employees will lose their trust in the } \\
\text { organization. }\end{array}$ \\
\hline & Talent and merit & $\begin{array}{l}\text { The placement of each individual in his right place is fundamental; } \\
\text { members should make an ongoing effort to boost their professional and } \\
\text { managerial capabilities. Only then can they expect to be involved in } \\
\text { succession-planning and the selection of candidates. }\end{array}$ \\
\hline & Peer envy & $\begin{array}{l}\text { We should believe that whoever is chosen to be promoted is the captain of } \\
\text { the boat we ride in together, so we should do whatever we can for his } \\
\text { success. }\end{array}$ \\
\hline \multirow[t]{2}{*}{$\begin{array}{l}\text { System } \\
\text { Factors }\end{array}$} & Values and beliefs & $\begin{array}{l}\text { Values and beliefs are the pillar of any organization; but in governmental } \\
\text { systems, they are flexible and professional values may be sacrificed for } \\
\text { the sake of baseless commitments. }\end{array}$ \\
\hline & Politicization & $\begin{array}{l}\text { The phenomenon of politicization is one of those things that } \\
\text { fundamentally disrupt the functioning of systems and organizations, } \\
\text { especially when the organization in question is the Ministry of Health, } \\
\text { which is stewardship for public health. }\end{array}$ \\
\hline
\end{tabular}

\subsection{Cultural factors related to the directors}

If a director does not guide the culture, the culture will guide him instead. Weak directors only join different currents because they are incapable of creating a current themselves. Directors should note that organizational culture should be in line with the organization's mission, goals and strategies. The measure of a good or bad culture is its consistency and compatibility with the organization's goals and plans and the alignment of the two is one of the major responsibilities of directors. This theme includes the following four themes; directors' job security, constructive competition, transparency and trust development and creating opportunities.

\subsubsection{Directors' job security}

Directors' concerns about the institutionalization of succession-planning and the empowerment of candidates for managerial positions and the subsequent threat to their own position makes them have no desire for implementing succession-planning so that they can maintain the status quo and preserve their own position within the organization. A 48-year-old male from the resource development department says about directors' job security: “...One of the problems with the issue of succession-planning is that many managers are currently afraid that implementing succession-planning will lead to a culture of succession-planning in which the potential successor develops greater capabilities than the existing manager and that they will thus end up undermining their own position as manager. In 
the macro management system, many try to downgrade people with potential and so the culture of successionplanning has not evolved. This problem is rooted in the managers' desire to remain in their managerial position. If a manager accepts from the beginning that his position is only temporary and for a limited duration, and so plans accordingly and with a set goal in mind, then succession-planning will become a crucial output of his performance in the role...".

3.1.2. Constructive competition

Some of the participants believed that the establishment of a succession-planning system within the organization motivates the managers to make greater efforts for empowering themselves and improving their professional and managerial capabilities and thus facilitates the achievement of desirable organizational goals and strengthens the managers' position as director and ultimately helps promote the organization's management system. A 51 -year-old male from the research department comments about constructive competition: “...When a manager feels that someone is being seen as a potential successor here ... I don't find anything wrong with it, it's not a problem, not a threat. It only makes the manager work harder to surpass others in all areas of work and I don't see anything wrong with it. The system should always be evolving...".

3.1.3. Transparency and trust development

Organizational values, beliefs and norms that are clearly defined and protected by the senior managers, tend to spread quickly. The transparency of functions and the development of trust form a strong and influential culture. Such culture leads to the loyalty of the members to the fundamental beliefs and values of the organization. A 51 year-old male from the Department of Vice-Chancellor for Treatment, talks about transparency and trust development: "...The institutionalization of a culture of succession-planning necessitates a set of manager selection criteria. We must have clear and fair criteria, which we often do, but still fail to respect the principles of ethics and equity. So if the system notices that you set criteria, implement them and respect the principles of equity, they will gradually form a culture. If you set a bunch of criteria but have no respect for justice, no matter how many times you announce those criteria to your employees, some won't take any notice of them and they will not form a culture...". Another 55-year-old participant from educational department commented: “...Transparency is in meritocracy. You are only transparent until you can openly defend your choices. So if you have the power to defend your choices, then you have made the right choices, chosen the right person of merit and not through bias and nepotism...".

3.1.4. Creating opportunities

Avoiding monopoly in both training and selection/appointment, creating opportunities and equal and fair conditions for all and the equitable distribution of management opportunities were among the important factors discussed by the participants. A 44-year-old manager from research department stated about creating opportunities: “...When the person in charge sees a worthy individual who is doing things and giving good ideas, he may feel that the new person can become a good manager; then he must support him all the way. Some managers believe in this and do exactly that, while some don't and do their best to put a stop to it...".

\subsection{Cultural factors related to the personnel}

This theme includes the following four themes; organizational identity and loyalty, trust in the organization, talent and merit and peer envy.

\subsubsection{Organizational identity and loyalty}

What distinguishes successful organizations from the rest is not only their ability to attract, train, foster, promote and sustain employees, but also to develop and maintain a profound sense of loyalty to the organization in their employees. In organizations with empowered cultures, the employees feel devoted to the organizational values and goals. Organizational loyalty is a person's sense of devotion and attachment to the organization. When there is organizational loyalty, the members of the organization are well-trusted and thus make an effort to protect the organization. A 61-year-old male from the health department argued about organizational identity and loyalty: “...The employees of this organization do not have a great organizational loyalty, because the managers are mostly brought in from outside. When the conditions are not conducive to the internal promotion of employees, organizational loyalty diminishes...".

\subsubsection{Trust in the organization}

A high level of trust in the organization somewhat compensates for weaknesses in other resources of promoting productivity, and makes the employees work harder. A high level of trust improves job satisfaction, creates an atmosphere of trust among the employees and improves synergy and cooperation among the employees and managers. A 56-year-old male from the food and medicine department comments about trust in the organization: “... Meritocracy is a criterion for both the transparent performance of managers and the equitability of the organization. It is as if driving the lorry of the organization is left to a driver without a heavy motor vehicle driving license while the driver with an HMV license is only given the job of driving the truck. Not choosing competent 
candidates for managerial positions may convey the message that the system does not trust its members, and if this behavior continues for different positions, a large number of the employees will lose their trust in the organization, and reduce the quality of their work. The personnel's trust in the managers is crucial to the formation and institutionalization of a succession-planning culture...".

\subsubsection{Talent and merit}

The modern world believes that human resources are the main competitive advantage of an organization, and comprise an organizational asset, and the valuable role of individuals within the organization is therefore more emphasized than in the past. Organizations in possession of a wealth of human resources in both specialized and management areas are better winners in today's competitive markets. The participating managers emphasized the importance of strengthening and promoting human resources. A 62-year-oldmale from the Department of ViceChancellor for Treatment says about talent and merit: “...We often hear from groups of experts or even managers that nobody is in their right position, or at least this and that person are not, and that this position is not suited for that person sitting there, he is not fit for it, etc. ..., which shows at least the importance of placing everyone in the right position. People should make an ongoing effort to boost their professional and managerial capabilities. Only then can they expect to be involved in succession-planning and the selection of candidates...".

\subsubsection{Peer envy}

Peer envy among the personnel was another important code extracted in the present study. An envious attitude prevents one from being happy about a colleague's promotion and may even lead to efforts for impeding their progress. Certain inappropriate characteristics become a barrier to effective communication between people and can disrupt the organizational plans. A 44-year-oldmale from the resource development department remarked about peer envy: "...We should believe that whoever is chosen to be promoted is the captain of the boat we ride in together, so we should do whatever we can for his and the boat's success. Unfortunately, this is not always the case...". Another 56-year-oldmale participant from the food and medicine department expressed a different view on the subject: "...Employees cannot be envious if the perfect candidate is chosen. Envy emerges when someone is chosen and appointed out of ten people with the exact same capabilities despite the presence of many better qualified candidates. This is when people get envious. No one compares themselves to someone who is way better than them, let alone envy them...".

\subsection{The cultural factors related to the system}

This theme includes the following two themes; Values and beliefs and Politicization.

\subsubsection{Values and beliefs}

The culture of an organization often reflects the values of the society and environment in which the organization exists. Values and beliefs are a cultural component rooted in the past. According to the participants, values and beliefs are the pillar of an organization, which are rather lenient in governmental systems, where professional values are sacrificed for the sake of baseless commitments. A 44-year-old male from the research department argued about values and beliefs: "...If we accept that expertise is the highest commitment, and the necessary though not sufficient requirement for selection and appointment, then there is no need whatsoever for the complete change of senior university directors just because a new president is inaugurated. The best person is the hardest-working one who seeks to accomplish the mission of the system; it doesn't matter if he's your friend and fellow or not. If we have different values instead of meritocracy and succession-planning, then we have sacrificed the system's performance for names. Clearly, people who do this are not one bit concerned about organizational excellence and lack commitment and take advantage of management opportunities for their personal gain and try to share these benefits with their relatives and friends too. This is where the problem lies...".

\subsubsection{Politicization}

The majority of the interviewees emphasized the importance of eliminating politics and politicization from the selection and appointment of directors. A 41-year-old male from the food and medicine department said about politicization: “...The phenomenon of politicization is one of those things that fundamentally disrupt the functioning of systems and organizations, especially when the organization in question is the Ministry of Health, which is responsible for public health; also, the problem becomes even more acute when it concerns succession-planning...".

\section{Discussion}

Organizational culture is considered an essential tool for the successful establishment of knowledge management in organizations (21). Succession-planning is a complex and challenging process that is influenced by the organizational culture in place (10). Although many studies have been conducted on the effect of organizational culture on different variables (21-23), the researchers' review of literature revealed very few studies on the relationship between organizational culture and succession-planning. In one study, Sabokroo proposed the "sense of 
threat to one's job" as an important problem and insisted that unless people are assured by their organization that succession-planning will not threaten their position, this program will not succeed (11). This was also highlighted in the present study, and most participants pointed out that directors felt threatened by the institutionalization of succession-planning. In another study, Dargahi et al. concluded that, in terms of organizational culture, the organizational structure in place in hospitals at the present moment allows for the adoption of strategies of change and evolvement and the successful use of modern technologies for these purposes (24). The present findings, however, suggest that the Ministry of Health is not yet culturally prepared for adopting succession-planning. A healthy organizational culture facilitates the establishment of an open, friendly, trusting, creative, collaborative, experimental, scientific, logical and modest environment where capabilities and potentials can be realized (7). For the effective improvement and spread of knowledge across an organization, organizational culture should be emphasized first and foremost (25). Decenze believes that organizational culture affects the decisions made about the organization's development goals and tools, and defines organizational development as an informed procedure through which the overall efficacy of the organization improves and the capacity for future change expands. Nevertheless, the results obtained on the effectiveness of organizational development remain unclear (26). A weak organizational culture that lacks flexibility, collaboration and creativity discourages the employees from having a desire for innovation, change and the creation of new ideas, and makes them fear the exchange and sharing of knowledge with others. A dynamic, collaborative and flexible culture that the members fully recognize and in which they trust, however, reacts well to changes and thus places the organization on the path of progress and excellence. The stronger the organizational culture is, the more successful the implementation of knowledge management systems will be (25). Alimardani et al. assert that the right organizational culture can transform an organization into an entrepreneurial organization (27). The study limitations were that it was observed that some participants were not comfortable in expressing their opinion for any reason. To solve this problem, they were assured that all of the received information will be completely confidential. Another limitation was that all of the participants were female.

\section{Conclusions}

The present study found the main barrier to the implementation of succession-planning to be directors' lack of job security. Due to concerns about potential threats to their own position as manager, directors resist the implementation of succession-planning. To resolve this problem, it is necessary to have a strict set of criteria for selecting and appointing the very first directors. Building a managerial culture in which the director realizes and accepts the fact that his position as manager is not permanent, but temporary and periodic, and that management ideas should always be updated and replaced with new ones, is an essential step in implementing a successionplanning system in organizations.

\section{Acknowledgments:}

We would like to express our gratitude to all the participants. The study was funded by a grant from Iran University of Medical Sciences (Ref. no.: IUMS/SHMIS-1391/307).

\section{Conflict of Interest:}

There is no conflict of interest to be declared.

Authors' contributions:

All authors contributed to this project and article equally. All authors read and approved the final manuscript.

\section{References:}

1) World Health Organization. The world health report 2000: health systems: improving performance. World Health Organization; 2000.

2) Rezaei Soufi M. The relationship between organizational culture and creativity as well as productivity of physical education faculty members of Payame Noor University. Applied Research of Sport Management. 2015; 3: 1-11.

3) Asoka AN. The role of organizational culture in the environmental awareness of companies. Journal for east European management studies. 2007; 12: 109-31.

4) Chin-loy $\mathrm{C}$, mujtaba BG. The influence of organizational culture on the success of knowledge management practices with north American companies. International business and economics, research journal. 2007; 6: 15-28. doi: http://dx.doi.org/10.19030/iber.v6i3.3350.

5) Monacko NJ. knowledge management in universities. Journal of Academy of UPM University. 2008; 10 : 42. 
6) Abzari M, Yarmohammadian MH. Relationship between Organizational Culture and Netiquette among Academic Staff in Isfahan University of Medical Sciences. Health Information Management. 2011; 7: 44354.

7) Schein EH. Organizational culture and leadership. John Wiley \& Sons; 2010.

8) Sadeghi A, Jafari H, Khodayari R, Pakdaman M, Mohammadi R, Ahadi nezhad B. A case study: the association between organizational culture with management knowledge in Hasheminezhad hospital Tehran. Hospital. 2012; 10: 8-16.

9) Gaufin JR, Kennedy KI, Struthers ED. Practical and affordable ways to cultivate leadership in your organization. J Public Health Manag Pract. 2010, 16: 156-61. doi: 10.1097/PHH.0b013e3181c8cb6310. PMID: 20150799.

10) Ponti MA. Hospital Chief Executive Officer Succession-Planning Practices. Walden University. 2013.

11) Sabokroo M, Gholipour A, Pourezat A. Force Field Analysis in Succession Planning for ITOC Company. Organizational Cultural Management. 2012; 10: 155-80.

12) Leibman M, Bruer RA, Maki BR. Succession management: The next generation of succession planning. People and Strategy. 1996; 19(3): 16.

13) Romejko MA. Key characteristics of a succession planning program at a government research center. Pro Quest. 2008.

14) Rothwell WJ. Effective succession planning: Ensuring leadership continuity and building talent from within: Amacom. 2010.

15) Barginere C, Franco S, Wallace L. Succession Planning in an Academic Medical Center Nursing Service. Nursing administration quarterly. 2013; 37: 67-71. doi: 10.1097/NAQ.0b013e31827857a7.

16) Kaye B, Jordan-Evans S. Retention in Tough Times. T+D. 2002; 56: 32-7.

17) Redeker JR. The legal overlay to succession planning. Employee Relations Law Journal. 2004; 30: $23-9$.

18) Ashkan NA, Pouran R, Iravan MA, Aslan N. Relationship Between Organizational Culture and Intellectual Capital Among Managers Of Imam Khomeini Relief Foundation (IKRF) Deputy For Support And Health. 2010. Payavard Salamat. 2013; 7(1).

19) Mehrtak M, Vatankhah S, Delgoshaei B, Gholipour A. Succession Planning in the Iranian Health System: A Case Study of the Ministry of Health and Medical Education. Global journal of health science. 2014; 6: 174. doi: 10.5539/gjhs.v6n5p174.

20) Rashidian A, Eccles MP, Russell I. Falling on stony ground? A qualitative study of implementation of clinical guidelines' prescribing recommendations in primary care. Health policy. 2008; 85: 148-61. doi: 10.1016/j.healthpol.2007.07.011.

21) Vazife Z, Tavakoli F. Assessing the association of Organizational Cultures Dimensions and Knowledge Management in Health Care Educational Organizations. Hospital. 2015; 14: 138-46.

22) Goudarzvand Ghegini M, Esmaeili S. The Study Of Organizational Culture Associated With Unified Theory Of Acceptance And Use Of Technology Model In Hospitals Of Rasht. Payavard Salamat. 2015; 9: 29-42.

23) Mohammad A, Abolfazl F, Seyed Hamid Gh. The Relationship between Organizational Culture and Organizational Entrepreneurship in Head Office of Sport and Youth, Qom province. Applied Research of Sport Management. 2015; 4: 25-36.

24) Dargahi H, Razavi SM. The role of organizational culture to implementing telemedicine Tehran University of Medical Sciences hospitals. Tehran University Medical Journal. 2005; 63: 99-107.

25) Amiresmaili M, Nekoei M, Khosravi S, Mirzaei S, Oroomiei N. The Relationship Between Organizational Culture Components And Knowledge Management: Case Study Of Kerman University Of Medical Sciences. Health Information Managmaent. 2015: 770-8.

26) DeCenzo DA, Robbins SP. Personnel: human resource management. Prentice-Hall; 1988.

27) Alimardani M, Farahani A, Ghasemi SH. The Relationship between Organizational Culture and Organizational Entrepreneurship in Head Office of Sport and Youth, Qom province. Applied Research of Sport Management. 2015; 4: 25-35. 